\title{
The Liames of Dressing in the Technological Age: Human-Computer Interactions and the Wearables
}

\author{
Andressa Caroline Sassarão Gonçalves $\mathbb{B}^{0}$, Dib Junior Karam, Suzana Avelar \\ School of Arts, Sciences and Humanities, University of Sao Paulo, Sao Paulo, Brazil \\ Email: andressacsgoncalves@gmail.com
}

How to cite this paper: Gonçalves, A.C.S., Karam Jr., D. and Avelar, S. (2020) The Liames of Dressing in the Technological Age: Human-Computer Interactions and the Wearables. Journal of Textile Science and Technology, 6, 190-199. https://doi.org/10.4236/jtst.2020.64016

Received: September 15, 2020 Accepted: November 13, 2020 Published: November 16, 2020

Copyright $\odot 2020$ by author(s) and Scientific Research Publishing Inc. This work is licensed under the Creative Commons Attribution International License (CC BY 4.0).

http://creativecommons.org/licenses/by/4.0/

\begin{abstract}
This article seeks to highlight some significant aspects that involve the cyber universe in today's society, linking these concepts with the evolution of fashion in the technological segment, since it is understood as an object of body extension, and technologies understood as extension support for this body. Is based on a supposed premise that it is necessary to understand that, when discussing the possibilities that wearables bring, one cannot neglect the pervasive performance of these devices permanently in the coexistence between humans and technology, to the point of one day not dissociating both?
\end{abstract}

\section{Keywords}

Garment, Technology, Wearables, Fashion, Body

\section{Introduction}

The widespread term to address wearable technologies in its broadest sense, is known as wearable technology [1], and encompasses clothes and accessories that through electronic and computational functions, are able to generate actions, as well as its processing, storage, communication and sensitivity capabilities can provide feedback to the user.

In prevalence, these actions require the use of the internet, and on this issue, it is worth mentioning that a good part of the wearables, are part of the IoT (Internet of Things) universe. These are things, according to the derivation of the term, which, through interconnectivity with an internet network, interact with each other and with humans, even remotely. The Internet of Things each year that passes becomes more intelligent and interactive and its ubiquity is undeniable [2]. It is present in people's daily lives in its most routine form, in the case of 
smartphones, or in devices for specific areas, such as health, in which devices allow remote monitoring by doctors with their patients, or in the security area, in which devices help governments to inspect the entry and exit of people at tolls and customs, and even in areas that require stock control, as in the case of stores, which have a system for tracking goods entrances and exits, and would still have several other examples to be cited. As for the wearables most consumed by the end consumer, the devices stand out, which are also known as gadgets. They are portable devices, such as the famous smart watches, bracelets and earwears. According to IDC (International Data Corporation) in the first quarter of 2020, there was a $16.2 \%$ growth in the bracelet category, while earwears grew $68.3 \%$, given that it is mainly due to the situation of the home office caused by COVID-19, since these more sophisticated headphones were highly expected by consumers due to its minimalist aesthetic, wireless connection, audio quality with noise reduction, which consequently helps in day-to-day productivity [3].

When expanding the term wearable, another aspect emerges, the e-textiles, also known as smart textiles. They are fabrics that, through the interaction with intelligent materials and computer technology, derive products that will react through actions, enabling computational operations and even functioning as conductors of electricity [4].

Other wearables also have more conceptual features, such as clothes with LEDs and accessories that project images or personalized messages.

One of the proposals of this article is to briefly discuss the body theme, starting from the approaches of Marshal McLuhan, a communication theorist and educator (1964, p. 17 apud [5]), based on the question that constitutes an extension of the body any device used by man in his tasks and in his social relations. This includes tasks and relationships, clothes, homes, media and transportation. It is possible to say that, the technology provided by wearables acts as an extension of the body itself through these devices, whether conceptual or functional, assisting in communicating about who we are, the lifestyle we lead and what we believe in, and space-time becomes an uniqueness of irreversible character, since man surrendered to the links of that evolution.

It becomes evident that since the emergence, as well as the accelerated improvement of technologies, significant characteristics of human behaviors have changed, either individually or in everyday social relationships. Whether behind the scenes or online interaction, there is a clear need for humans to update themselves in the face of news, the recycling of launches and, increasingly, to cancel other human resources, currently delegated to machines and/or computers.

It does not intend to establish a technological determinism, but understands that the way society deals with constantly changing technology that is dynamic and there is a constant evolution and adaptation of possibilities that support life in the technological age.

\section{Human-Computer Interaction}

The human mind has become a direct force of production and not just a decisive 
element in the productive system, thus, what it thinks and how it thinks is expressed in goods, services and material and intellectual production [6]. Computers, communication systems, decoding and genetic programming have become amplifiers and extensions of the human mind and the integration between minds and machines fundamentally changes the way we live, and therefore the way we die [6]. Thus, it is possible to state that, both cultural and institutional contexts together with intentional social action, interact decisively with the current technological system, which, in turn, incorporates its own logic that is recognized by the ability to transform information into a common information system, processing them at increasing speeds and capacities and lower costs, in a potentially ubiquitous distribution network [6].

Ubiquitous computing defines the current state of daily coexistence of human-computer interaction, a state that, Mark Weiser ${ }^{1}$ foresaw in the $90 \mathrm{~s}$, a future where computers would integrate the most diverse objects such as "clothing labels, coffee cups, light switches, pens, etc., invisibly to the user" [7].

Going deeper into the question of human-computer interaction, humans have been anguished since technology began to occupy jobs in the last century regarding the potential of machines and/or computers. Whether in repetitive processes, or in works that minimize and optimize human cognition, the human mind has surrendered to technology and has left many processes behind, from memorizing phones, to do calculations, to more complex and substitutive processes of human intervention. And the trends are even more revealing, when terms like cognitive technologies, fast data, machine learning and automation start to be present in everyday life, and humans even wonder how the world has survived so long without these resources.

Extending human capacities and the limitations of the body have become a race against time, and we can mention the discussions proposed by Costa [8] about the body as the background of the essence of modern technique, in which "it must be forced according to the use for which we intended it", in this way, engineering, artificial insemination, prostheses and aesthetics, define, enable, manipulate, prolong and repair human existence and survival.

The revolution that culminated in the point where humanity reached today, happened with the end of the Second World War, in 1945, through the creation of the first digital computers [9]. Scientists, programmers and operators were divided between giving commands to huge machines housed in air-conditioned rooms, and physically altering circuits, so that these electronic devices could complete their calculations. In the following decade, computer technology was still, in its prevalence, scientific and accounting applications. The interaction with the computer was minimal, since there were no data processing methods almost as instant as today [9]. In the 1970s, computer technology arrived at companies and screens connected to a central computer became common, and these were interconnected in networks [9]. That's when the interest in Human ${ }^{1}$ Known as the father of Ubiquitous Computing, for having given rise to the term in his seminal article The Computer for the 21st Century, in 1991 (SACCOL; REINHARD, 2007). 
Computer Interaction became exponential, and then in the 1980's the first graphical interfaces appeared in the form of computers marketed for personal use and the internet started to grow [9]. In the 90s, the world network, better known as the Word Wide Web emerged, and revolutionized the file sharing process [9]. Although connections were improving mainly in the West and the United States, with the arrival of the 21 st century the connection to the web is global [9].

And at what point does all of this converge on wearables? As Benyon said, a technology should not be just a technology, but a technology linked to a good business model at an opportune time. and quotes the term "information utensils", which broadly means: everyday things that are functional; utensils must have a clear function even if their usability is multiple [9]; utensils that work together without the need for central control; its use must be simple and intuitive; perform the function or functions for which they were assigned in an agile and efficient manner; utensils should be understood as something so common that one does not think about how to use them, just use them; and finally, they must be personal and portable.

The first "utensil" to think about after these defined characteristics are smartphones, but what if human beings didn't have to limit themselves to just that? It is with this assumption that wearables gain visibility.

Through the hybridization that the technologies allow, proposing innovative dialogues in fashion becomes essential for the advancement of the segment, since, in addition to the aesthetic issues strongly guided in the fashion universe, clothing in general combined with these technologies can help in daily life on several fronts, from fashion itself as an element of style, to safety, medical, wellness and sport, lifestyle and communication. And, for all this to work, new needs arise in the creation, such as Interaction Design (ID) that is directly related to the design of computer-based systems. The ID consists of "creating user experiences that improve and expand the way people work, communicate and interact” $[10]$.

With that, it is possible to suggest an analogy with the clothes used in everyday life. People choose the clothes that will represent their beliefs and their style every day, and these elements substantiate their assertiveness through non-verbal communication, as important today as spoken communication, so to speak. Smart watches, monitoring bracelets, accessories to control living with some disease, or even as an accessory of modern and conceptual fashion, are increasingly gaining space in this body wrap, and finally, the prognosis of Santaella [11] is confirmed by arguing that the consequences and implications that humanity has been going through, "will probably be more profound in anthropological terms than those that the Neolithic revolution provoked" and complete that the mutations in the dimensions of our body, sense and brain that we reach, "creates a new anthropomorphism whose routes of sensitivity and intelligibility we cannot fail to explore". 


\section{Trans-humanism, Artificial Intelligence and Virtual Reality}

There are many terms for the denomination about understanding the transformation of what is recognized as human. This awareness is currently guided by the expression "transhumanism" which, it was called for a long time and by several authors by "post-humanism" [12] and, guided by these diverse currents, it argues that the term encompasses from dystopian scenarios in which humans would be enslaved by automatons (MORAVEC ${ }^{2}, 1988$ apud [12]); post-evolutionary strategies that would redesign the mortal body for extraterrestrial situations (STELARC ${ }^{3}, 1994$ apud [12]); that humans were traveling a path to become bionic (ASCOTT ${ }^{4}, 1995$ apud [12]); to thoughts that defend that humans will arrive at a given moment when it will be impossible to distinguish what is human and what is technology, understanding this scenario through virtual reality, global communication, prosthetics and nanotechnology, neural networks, genetic algorithms, manipulation genetics and artificial life (PEPPERELL ${ }^{5}, 1995$ apud [12]).

The term still goes through less unusual situations like implantation of microchips, pacemakers and prostheses.

With regard to Virtual Reality (VR), Santaella [11] defines them as interfaces made possible by means of hybrid landscapes, since environments and spaces biological mix with images, spaces and environments synthesized, also known as cyberspace.

An example between the convergence of wearables and VR can be exemplified by The Hug Shirt ${ }^{\mathrm{TM}}$, as shown in Figure 1, created by the company CuteCircuit. It is a shirt with built-in sensors that detect skin heat and heart rate while actuators recreate the feeling of a hug that will be simulated due to stimuli in various parts of thebody, recreating the feeling of presence and union between two people [10].

The convergence between fashion and technology goes much further, and in Silicon Valley a fashion week was launched, called Silicon Valley Fashion Week. In 2015 the catwalk of the event was shared between human models and drones, as shown in Figure 2, which reinforces that the fashion is in technology as well as the opposite is also true in this universe of extraordinary possibilities.

As Gonçalves quotes, the modern narrative between fashion andtechnology, enables a dichotomous perspective between the futuristic and the current, since, as technology advances, humanity increasingly distances itself from the impossible and fictional [14].

Not only is there an intrinsic inclination for consumers to incorporate wearables, as well as all types of technology in their analog realities, but this sphere of dressing and communicating in a virtual/digital/automated reality creates new ${ }^{2}$ MORAVEC, Hans. Mind Children. Cambridge: Harvard University Press, 1988.

${ }^{3}$ STELARC. Da strategiepsichologiche a cyberstrategie: prostetica, robotica ed esistenzaremota. In: CAPUCCI, Pier Luigi (org.). Il corpotecnológico. Bologna: Baskerville, 1994. p. 61-76.

${ }^{4}$ ASCOTT, Roy. Le retour à la nature II. In: Poussant, Louise (org.). L'esthétique des arts médiatiques. Quebec: Presses de l' Université du Quebec, 1995. p. 437-451.

${ }^{5}$ PEPPERELL, Robert. The post-human condition. Oxford: Intellect, 1995. 


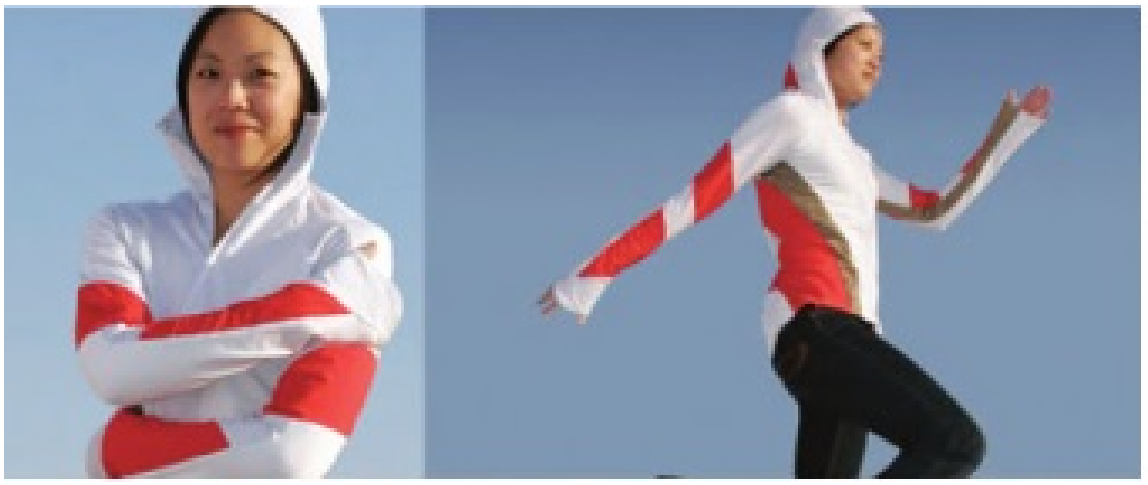

Figure 1. The hug shirt ${ }^{\mathrm{TM}}$. Source: Rogers, Sharp and Preece (2013, p. 114) [10].

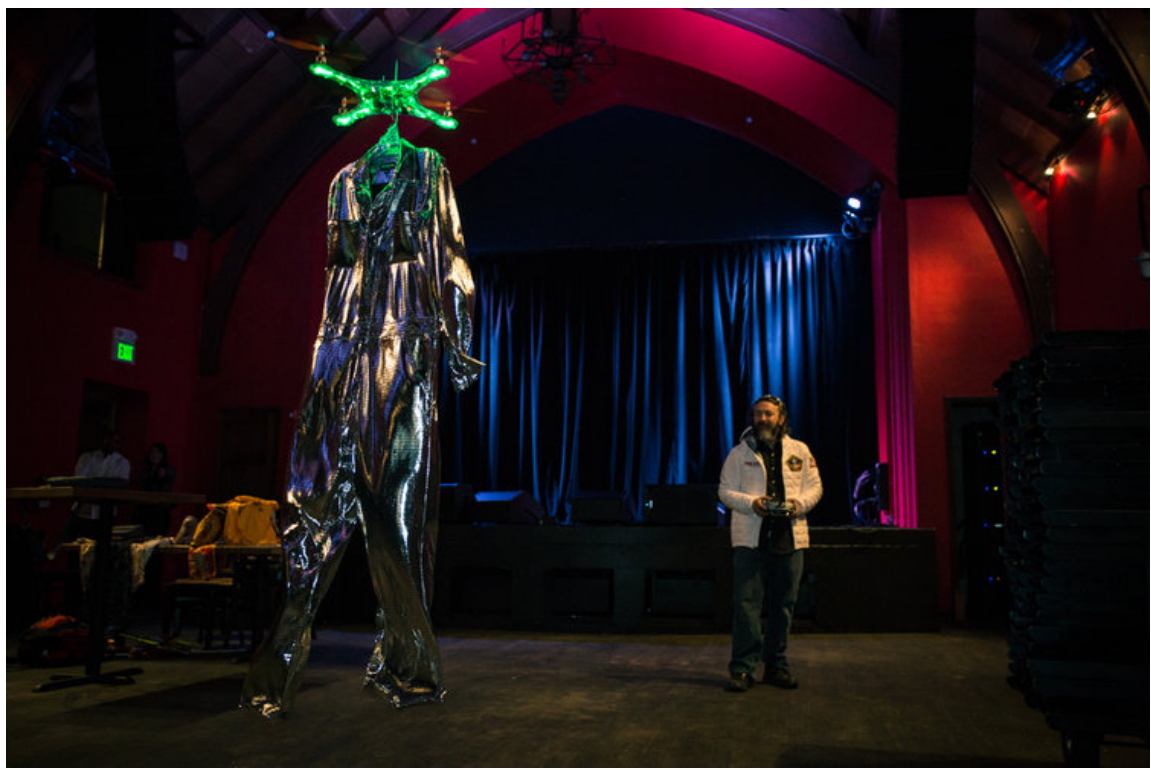

Figure 2. Drone "parading" look at Silicon Valley fashion week. Source: Betabrand ${ }^{6}$ (2015 apud CARSON, 2015 [13]).

ways of understanding a new world guided by more receptive values, such as the analogy between human models sharing walkways with robots, and society incorporating into their finite lives, extenders of their human capabilities.

In this sense, we may understand fashion and wearable technologies as an emergent quality of actor. This actor is that body involved and cooperating with, through and within some digital apparel, functioning in everyday life, intertwined with digital practices. That body acts as an active potent object, becoming one complex subject-object in the net, actuating in real time, where there is some symmetry between subject and object. According to Lemos [15], in Theory Actor Net (TAN), this symmetry is a quality of IoT (Internet of Things), where that body generates and uses datas, makes decisions, constituting and being part of a big metadatas complex.

This body is acting in a diversity of spaces (Physical and virtual), in a public ${ }^{6}$ Betabrand. Betabrand tests out the drones ahead of Silicon Valley Fashion Week. (2015). 1 photography. 
presence, which fashion has a great part of it.

This space is composed by human and non-human elements, temporary or permanent, frequently accessible, intertwining the complex net which is established by the flux of information, with the circulation of those actors. Therefore, wearable technologies help to constitute this "thing" produced together with a living body.

And by the way, in the field of artificial intelligence, each year that passes the progress in this area becomes more impressive. "Thinking computers" are no longer new, but there is a race against time in related to the human brain. $\mathrm{Hu}$ man-looking robots, called of androids, are a reality for various purposes, and even robots with the appearance of a specific human, called of geminoids, as the case of Hiroshi Ishiguro. $\mathrm{He}$ is an expert in the field and created his own geminoid, in addition to a laboratory dedicated only to the promotion of studies in this area, as well as the creation of other geminoids, as shown in Figure 3.

According to Heaf [17], what differs Hiroshi Ishiguro's thinking from that of most engineers and scientists working on robotics and artificial intelligence projects is that for him the priority is not only the functional capacity of creation, on the contrary, Ishiguro defends the idea that if robots are built to interact with humans, they have an obligation to look like humans, in behavior and aesthetics. Still according to that thought, the exponential overcoming of the limitations resulting from physical bodies through new technologies is a major milestone in evolution, but it is not about technological evolution, but about human evolution [17].

This cut may not even seem to compete with the fashion universe, given its biological, scientific and, of course, technological emphasis, however, the growth of partnerships between fashion and technology brands is notable, as is the case with Gucci, which in February 2018, promoted a parade based on the book "Cyborg Manifesto" by Donna Haraway [14]. Figure 4 shows one of the models of the fashion show.

Science and technology in association have not yet managed to reproduce

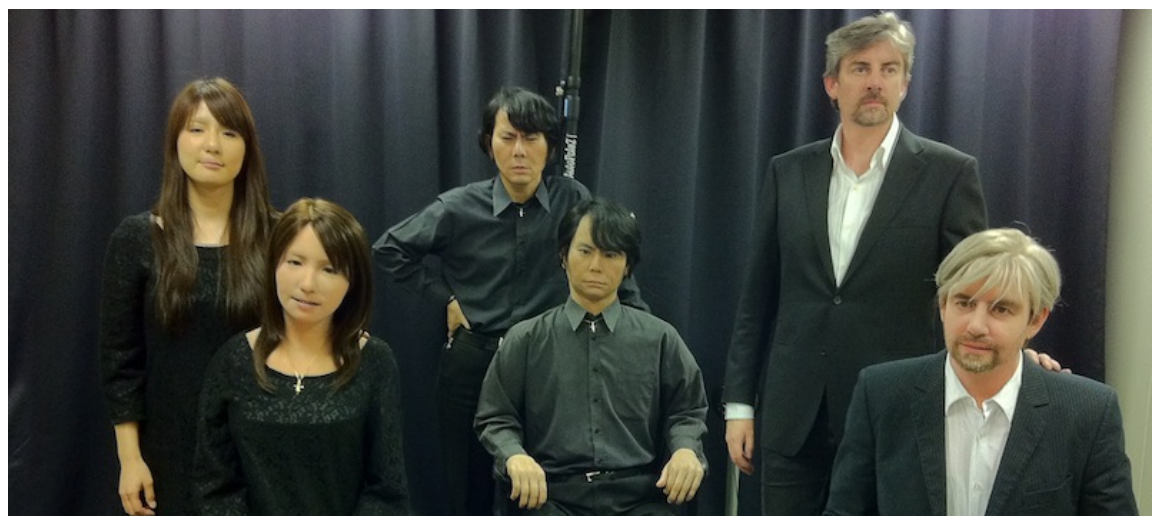

Figure 3. Hiroshi Ishiguro in the center (standing) with his geminoid. Beside you two more creations inspired by real people. Source: Official site Laboratory Hiroshi Ishiguro [16]. In: <http://www.geminoid.jp/en/index.html>. Access on 14 Sept. 2020. 


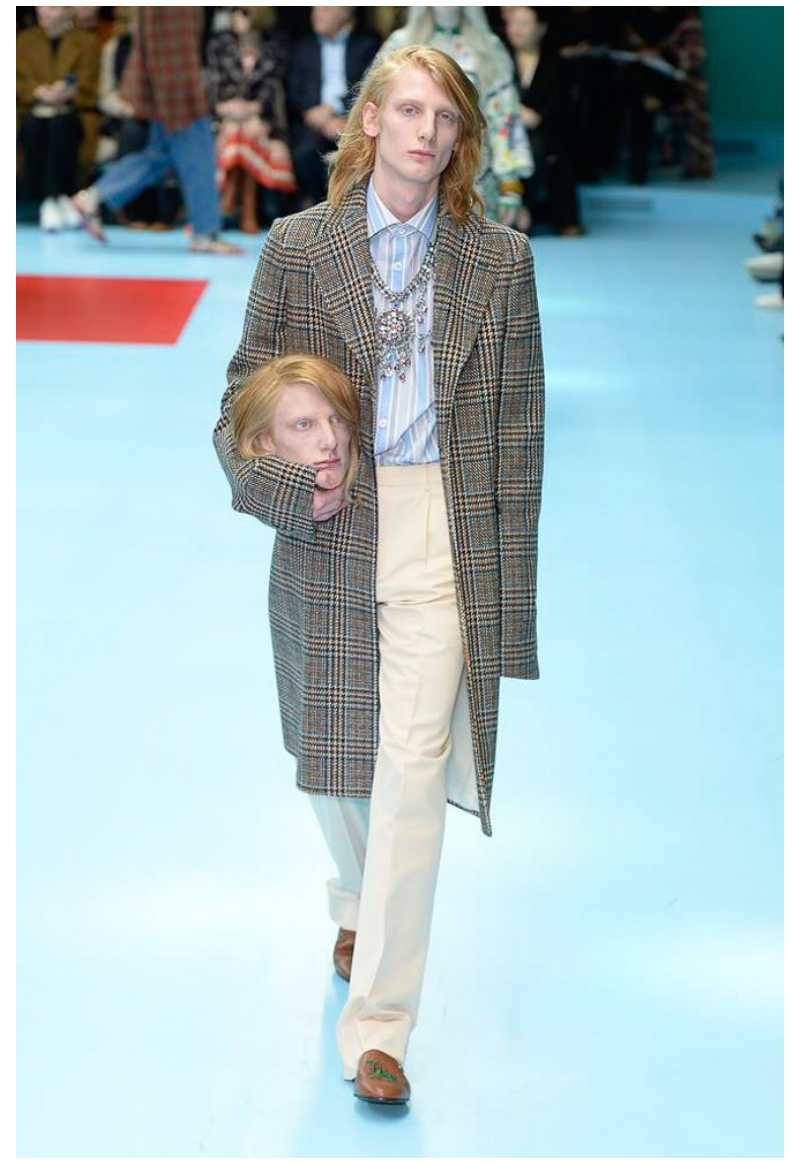

Figure 4. Male model Gucci, holding replica of his head. Source: Portal FFW, Fashion Forward [18] (2018).

characteristics linked solely to the human brain, such as feeling, sensations and autonomy, but, in summary, it is remarkable that the growth of technologies through multimedia and devices, reflects our deepest desire to design and expand the possibilities of cognitive functions in our externalized senses through the available technologies and with the advances of more refined research on this subject.

\section{Partial Completion}

Technological advances have revolutionized the fashion industry throughout history, even before wearables were possible. Smart and technological textiles are part of the evolution of the textile industry, and DuPont ${ }^{7}$ is an example to be highlighted, when still in the 1940s it created one of the most innovative fabrics, Nylon. For a while it was used specifically for women's tights, then for sportswear in general, until during World War II its production became exclusive, and at the end of that period the company became a pioneer in marketing focusing on the final costumer and in the development of new fibers that once ${ }^{7}$ World leader in innovation and market-oriented science. Active in more than 90 countries over two centuries, and in several markets, such as agriculture, nutrition, electronics and communications, security and protection, home and construction, transport and clothing (DUPONT, 2020). 
again restored all understandings of innovative fabrics [19].

It is possible to compare the arrival, permanence and progress in the wearables trade with the small and profound advances in the history of textile fibers. The concern to promote revolutionary creations comes from the desire to facilitate everyday life, to survive, and to create new connections between the known and the unknown, and in this sense, the fashion industry has been doing its homework.

The research started from a purpose to present plausible definitions about what is wearable technology, and it was branching among the universes that orbit this reality. To talk about the commercial and conceptual context of these products, it is important to understand their viability on a daily basis. Then, paying attention to the consequences of human interaction with technology becomes paramount, since this coexistence becomes more and more natural, and finally, finding examples that cross between these topics in a fluid way.

To transcend the dematerialization of the body through innovations in means of communication, even as overcoming the barriers of limitation of the body translates what Santaella [20] says about the "symptoms of the culture of our time", when modernity seeks to untie space-time through resources guided by technology, from the use of the internet to guide various daily activities and which acts as a direct line connecting people, wherever they are and their unusual presence in IOT's, up to wearable technologies, who come to combine and also innovate the fashion cycle. In this universe there is still the incessant race for the evolution of research in virtual reality and artificial intelligence, until we reach perhaps a given moment as predicted by Pepperell (1995 apud [12], p. 192) the convergence of the artificial and the real will be indistinguishable.

\section{Conflicts of Interest}

The authors declare no conflicts of interest regarding the publication of this paper.

\section{References}

[1] Neuman, M. and Sazonov, E. (2014) Wearable Sensors: Fundamentals, Implementations and Applications. Elsevier, Amsterdam, XI.

[2] Santaella, L., Gala, A., Policarpo, C. and Gazoni, R. (2013) Desvelandoa Internet das Coisas. Revista Geminis, 1, 19-32.

[3] International Data Corporation (2020) Earwear and Wristbands Drive First Quarter Growth in the Worldwide Wearables Market, Says IDC. https://www.idc.com/getdoc.jsp?containerId=prUS46432620

[4] Berglin, L. (2013) Smart Textiles and Wearable Technology: A Study of Smart Textiles in Fashion and Clothing. Swedish School of Textiles, University of Borås, Borås.

[5] Avelar, S. (2011) Moda: globalização e novastecnologias. 2nd Edition, Estação das Letras e Cores, Editora SENAC Rio, Brazil.

[6] Castells, M. (1999) A Sociedadeem Rede. 6th Edition, Paz e Terra, São Paulo. (A era 
da informação: economia, sociedade e cultura, 1).

[7] Araújo, R.B. de. (2003) Ubiquitous Computing: Principles, Technologies and Challenges. Brazilian Symposium of Computer Networks and Distributed Systems XXI, Natal. Mini Course: Textbook. Natal, RN, UFRN/DIMAp/UnP, Brazil, 45-115.

[8] Costa, M. (1997) Corpo e Redes. In: Domingues, D., Ed., Aarte no século XXI, FundaçãoEditora da UNESP, São Paulo, 303-314.

[9] Benyon, D. (2011) Interaçãohumano-computador. 2nd Edition, Pearson Prentice Hall, São Paulo.

[10] Rogers, Y., Sharp, H. and Preece, J. (2013) Design de interação: Além da interaçãohumano-computador. 3rd Edition, Bookman, Porto Alegre.

[11] Santaella, L. (1997) O homem e as máquinas. In: Domingues, D., Ed., Aarte no século XXI, FundaçãoEditora da UNESP, São Paulo, 33-44.

[12] Santaella, L. (2003) Culturas e artes do pós-humano: da cultura das mídias à ciber-cultura. Paulus, São Paulo.

[13] Carson, B. (2015) Silicon Valley Fashion Week is Real, and It Stars Drones and Robots Instead of Models. Business Insider, New York, 11 May 2015.

https://www.businessinsider.com/silicon-valley-fashion-week-is-put-on-by-dronesnot-models-2015-5

[14] Gonçalves, A.C.S. (2019) The Human-Computer Interaction through Wearable Technology. School of Arts, Sciences and Humanities, University of Sao Paulo, Sao Paulo.

[15] Lemos, A. (2010) Vocêestáaqui! Mídialocativa e teorias "materialidades da comunicação" e "ator-rede". RevistaComunicação e Sociedade, São Bernardo do Campo, SP, Metodista, year 32, 5-29.

[16] Hiroshi Ishiguro Laboratories (2020). http://www.geminoid.jp/en/index.html

[17] Heaf, J. (2018) What Does It Mean to Be Human? A Dialogue with Robotics Professor Dr. Hiroshi Ishiguro. GQ Fashion, London, 13 July 2018.

https://www.gqmagazine.co.uk/article/gucci-performers-hiroshi-ishiguro

[18] PORTAL FFW-FASHION FORWARD (2019) São Paulo, c2018a. Desfiles. Últimosdesfiles. Ver todos. Designer. Gucci. Inverno 2019 RTW Milão. https://ffw.uol.com.br/desfiles/milao/inverno-2019-rtw/gucci/1688132/colecao/6/

[19] O’Connor, K. (2010) How Smart Is Smart? T-Shirts, Wellness, and the Way People Feel About "Medical". Textile, 8, 50-66. https://doi.org/10.2752/175183510X12580391270029

[20] Santaella, L. (2004) Corpo e comunicação: sintoma da cultura. Paulus, São Paulo. 